\title{
A construção de histórias do futebol no Brasil (1922 a 2000): reflexões
}

\author{
João Manuel Casquinha Malaia Santos[1] e Maurício Drumond[2]
}

\begin{abstract}
Resumo
São poucos os balanços da historiografia do futebol brasileiro. Este artigo procurou realizar um necessário levantamento crítico de algumas das principais obras da história do futebol no Brasil, não apenas para avaliar o estado da arte da produção sobre o tema, mas também a fim de estimular reflexões metodológicas e conceituais. Buscou-se perceber como sua memória foi elaborada por aqueles que escreveram suas histórias.
\end{abstract}

Palavras-chave: historiografia; futebol; memória.

\section{La construcción de historias del fútbol en el Brasil (1922 a 2000): reflexiones}

\section{Resumen}

No hay muchos estudios acerca de la historiografía del fútbol brasileño. En este artículo se pretende realizar un estudio crítico de algunas obras importantes en la historia del fútbol en Brasil, no sólo para evaluar el estado de la producción sobre el tema, sino también para estimular reflexiones metodológicas y conceptuales. Hemos tratado de entender cómo la memoria del fútbol brasileño ha sido elaborada por los que escribieron sus historias.

Palabras clave: historiografía; fútbol; memoria.

\section{The construction of soccer stories in Brazil (1922 to 2000): reflexions}

\begin{abstract}
There are few studies about the historiography of Brazilian soccer. This article aimed at performing a necessary critical reflection over some of the most important works of soccer history in Brazil, not only to evaluate the production state of art on the theme, but also to stimulate methodological and conceptual reflections. It also sought to highlight how the memory about Brazilian soccer was developed by those who wrote its histories.
\end{abstract}

Keywords: historiography; football; memory.

\section{La construction d'histoires du football au Brésil (1922-2000): réflexions}

\section{Résumé}

Il ya peu d'études sur l'historiographie du football brésilien. Cet article vise à effectuer une réflexion critique nécessaire sur quelques-unes des oeuvres les plus importantes produites de l'histoire du football au Brésil, non seulement pour évaluer létat de lart de notre production historiographique sur le thème, mais aussi de stimuler la réflexion méthodologique et conceptuel. Il vise également à souligner la façon dont la mémoire sur le football brésilien a été développé par ceux qui ont écrit ses histoires.

Mots-clés: historiographie; football; mémoire. 


\section{À}

$\mathrm{s}$ vésperas da estreia da seleção brasileira de futebol no campeonato sul-americano de 2011, o repórter Tino Marcos, pertencente ao mais conhecido canal de televisão do país, elaborou uma matéria em que abordaria, uma a uma, as conquistas do selecionado nacional neste torneio. No primeiro dia, a reportagem seria sobre a primeira conquista brasileira, em 1919. Com imagens de dribles, malabarismos e gols de jogadores vestidos com a camisa da seleção brasileira em diferentes gerações, o texto, lido em off, destacava a importância do assunto:

De onde vem esse jeito tão brasileiro de se mexer diante de uma bola? Vem da mistura. De um país mestiço que soube como nenhum outro levar ao futebol heranças europeias e africanas. Garrincha, Ronaldo, Romário. Gênios. Mestiços. Descendentes de um certo Arthur.

A libertação dos escravos, em 1888, provocou uma crise em parte das fazendas do Sul do país. Muitos dos alemães que viviam por lá vieram tentar a sorte em São Paulo. Entre eles, Oscar Friedenreich. Ali conheceu uma ex-escrava que, segundo os historiadores, era de uma beleza que valia a quebra de um preconceito. ${ }^{1}$

O texto faz alusão aos "descendentes de um certo Arthur". Trata-se de Arthur Friedenreich, o jogador mulato que marcou o gol do primeiro título sul-americano da seleção brasileira, em 1919, contra o Uruguai. Seu pai era alemão e sua mãe ex-escrava, estando assim as heranças europeias e africanas em seu sangue. A matéria foi exibida no noticiário Jornal Nacional, com maior audiência no país. Buscava-se mexer com as emoções dos espectadores, lançar "cápsulas de história", cheias de potencial emotivo e auxiliando decisivamente na criação de memória social a respeito do tema e no aumento da audiência da competição.

Neste cenário, deve-se indagar: de onde vem a ideia de que existe um jeito tão brasileiro de se mexer diante da bola, resultante da mestiçagem entre negros e europeus? Essa questão é diretamente relacionada à elaboração de uma memória que se cristalizou durante décadas na sociedade brasileira. Outros mitos são criados e repetidos insistentemente por meios de comunicação ou até mesmo por alguns dos autores que se propõem a escrever uma história do futebol no Brasil. Máximas como o fato de Charles Miller ser o pai do futebol, deste ter sido inventado pela elite e passado para o povo, entre tantas outras conhecidas por aqueles que costumam acompanhar este esporte no país por meio dos mais diversos meios de comunicação.

Nos últimos anos, tem acontecido um grande avanço no sentido da realização de pesquisas mais aprofundadas sobre os problemas relacionados ao passado do futebol no Brasil, apesar disso, são poucos os balanços de sua historiografia. Torna-se necessário um levantamento crítico de algumas das principais peças produzidas com a intenção de abordar questões da história de tal esporte, não apenas para avaliar-se o estado da arte de nossa produção historiográfica sobre o tema, mas também para estimular reflexões metodológicas e conceituais. ${ }^{2}$

Por ser a análise de um corpus de história dentro de um determinado recorte, duas questões essenciais para a reflexão proposta devem ser levadas

TTino Marques, Jornal Nacional, 28 de junho 2011.

2Fernando Novais, Aproximações: estudos de história e historiografia, São Paulo, Cosac Naify, 2005. 
em consideração: o recorte que se debruça sobre a produção elaborada no século XX — precisamente entre 1922 e 2000 —; e o limite de espaço imposto em um artigo acadêmico. Devido a esses dois pontos, é impossível esgotar o estudo de todas as investigações da história do futebol no Brasil. Por isso, foram selecionados, para esta análise, os textos considerados como os mais significativos tanto para sua época quanto em sua função de criação de memória social às gerações futuras. As obras que não foram analisadas não tiveram, necessariamente, menor importância do que aquelas levantadas, as quais apenas nos parecem de maior potencial analítico.

Em segundo lugar, centramo-nos na produção oriunda do eixo Rio-São Paulo, devido, novamente, ao limite deste trabalho e em função do maior alcance e influência que as obras desses centros tiveram sobre a historiografia do futebol no Brasil. Apesar desta análise ter seu foco na produção acadêmica oriunda dessas duas cidades, ao tratar-se daquela nacional sobre o tema, isso é realizado de modo consciente pelos motivos mostrados, enquanto muitos trabalhos executam o mesmo na ilusão de estarem representando todo o país.

\section{Neste cenário, deve-se indagar: de onde vem a ideia de que existe um jeito tão brasileiro de se mexer diante da bola, resultante da mesti- çagem entre negros e europeus?}

Optou-se pela análise cronológica dos textos, contextualizando-os, observando as ferramentas metodológicas utilizadas por cada autor, suas principais contribuições e lacunas. Até o final dos anos 1970, as histórias do futebol brasileiro eram basicamente escritas fora da academia, principalmente por jornalistas e ex-atletas. Após esse período, o tema passou a interessar às ciências sociais e humanas. Primeiramente, atraindo a atenção de sociólogos e antropólogos e, posteriormente, de historiadores. O objetivo deste trabalho foi além da análise crítica das obras. Buscou-se perceber como vem sendo elaborada a memória criada por aqueles que escreveram histórias do futebol brasileiro. Espera-se, assim, conseguir apontar alguns caminhos que auxiliem na discussão da história do futebol para que continue havendo avanços.

\section{Primeira geração: anos 1920/1930}

O texto escolhido para iniciar o estudo não aborda exclusivamente o futebol, mas os esportes. No entanto, a importância de seu conteúdo e a relevância do veículo de publicação tornam obrigatória a sua presença. Escritos por Roberto Trampowski Junior e Francisco Calmon, dois textos compunham o verbete "Desportos" do Diccionário Histórico, Ethnographico e Geographico do Brasil, organizado pelo Instituto Histórico e Geográfico Brasileiro (IHGB), publicado em 1922, ano da celebração do centenário da independência do país.

No primeiro, Trompowsky defendia a ideia de que apenas em 1894 se apresentaria a "fórmula desportiva capaz de operar o milagre de uma 
transformação necessária e profunda nos hábitos, na educação da mocidade", com a "introdução do foot-ball": o "desporto-leader". ${ }^{3}$ Este seria o

desporto mais assimilável, mais adaptável aos caracteres ingênitos, físicos e psíquicos da mocidade brasileira, entre os quais avultam a nervosidade latina e a combatividade indígena. ${ }^{4}$

O texto seguinte, de Francisco Calmon, é um típico trabalho com características da escola metódica francesa, ${ }^{5}$ o qual destaca a formação das principais estruturas de poder do esporte no Brasil. Calmon clama pelo "admirável esforço e tenacidade" da Confederação Brasileira de Desportos (CBD), "entidade máxima da desportividade no Brasil". ${ }^{6}$ Em seguida, apresenta o nome de todas as ligas de futebol brasileiro filiadas à CBD, e de seus principais clubes. $\mathrm{O}$ autor reforça o papel de clubes dirigidos por importantes figuras da elite brasileira, como o Fluminense, presidido por Arnaldo Guinle. Se no primeiro texto Trampowsky reforça o discurso do IHGB sobre a formação miscigenada do brasileiro, o texto de Calmon resulta em uma produção descritiva, factual, cronológica e não problematizante sobre tal esporte.

Na década seguinte, outra obra de relevância tomou uma direção contrária. Foi escrita pelo ex-jogador Floriano Peixoto Correa, em 1933, quando houve a profissionalização oficial de parte dos atletas de futebol e em um contexto político de democratização devido à eleição de uma nova Assembleia Constituinte e o prospecto de uma nova Constituição, além do retorno ao estado de direito. O livro assumiu um tom de denúncia e preocupou-se em discutir as questões que se relacionam com o futebol, principalmente no Rio de Janeiro e em São Paulo. O trabalho assume a utilização da história como ferramenta para o entendimento de problemas que tocam as Grandezas e misérias do futebol brasileiro, título da obra.

Dedico este livro a memória de meus companheiros de futebol que morreram na indigencia depois de terem contribuido para a glorificação do soccer nacional - humildes operários que a custa de sacrifícios enormes, inclusive o da própria vida, legaram aos clubs os estádios de cimento armado que estes ostentam hoje nos diversos bairros aristocráticos das principais cidades do paíz, com salas doiradas e pistas de baile para o gozo exclusivo dos diretores e dos sócios ricos. [...] Dedico-o finalmente, aos companheiros mutilados que arrastam hoje a sua miséria física de homens invalidos para outras atividades, mendigando o pão de cada dia, esquecidos e desprezados por aqueles que exploraram seu vigor e sua mocidade. ${ }^{7}$

Max Valentim e Paulo Várzea, jornalistas esportivos do jornal carioca O Imparcial, que produziam trabalhos históricos sobre o esporte, escreveram na abertura do livro. Valentim pedia para que Correia não ocultasse "figura de

\footnotetext{
${ }^{3}$ Roberto Trampowsky Junior, Francisco Calmon, "Desportes", In: Diccionário histórico, ethnographico e geographico do Brasil, Rio de Janeiro, Instituto Histórico e Geográfico Brasileiro, vol. 2, 1922, p. $412-418$. 4/bidem, p. 413

${ }^{5}$ Para maiores informações sobre a escola metódica, ver Guy Bourdé, Hervén Martin, As escolas históricas, Lisboa, Europa-América, 1983.

${ }^{6}$ Roberto Trampowsky Junior, Francisco Calmon, op. cit., p. 414

${ }^{7}$ Floriano Peixoto Correia, Grandezas e misérias do nosso futebol, Rio de Janeiro, Flores e Mano Editores, 1933, p. 14.
} 
ninguém, por mais que esse ninguém seja importante ou poderoso". ${ }^{8}$ Já Paulo Várzea mencionava que o livro de Floriano expunha:

[...] as grandezas e misérias de uma época que ainda hoje clama contra a casta de barões feudais, vaidosos, autoritários, abancados com seus vassalos nas diretorias dos clubes e nos guichets dos portões, casta sempre pronta a sugar o sangue do jogador de futebol, a devorar-lhe a saude e a raspar as fortunas generosamente deixadas nas bilheterias pelo publico, em troca do prazer que lhe proporcionou o operário da pelota - único personagem leal desse espetáculo singularmente popular que há 20 anos se transformou num inesgotável manancial de dinheiro para os sindicatos de cavalheiros de mãos muito pouco honradas. ${ }^{9}$

O livro Grandezas e misérias do futebol brasileiro deu ao esporte a direção das discussões política e social mais amplas em curso na sociedade brasileira, tratando-se de uma obra fundamental. Apontando a importância da miscigenação para a formação do jogador de futebol nacional, reforçando o papel da elite e das estruturas políticas no futebol do país, ou denunciando as mazelas deste esporte, os textos da primeira geração influenciaram sobremaneira as gerações futuras.

\section{Segundla geração: anos 1940/1950}

Em 1950, o Brasil recebeu a IV Copa do Mundo de futebol masculino. Ao ser iniciado o campeonato, em 24 de junho, duas das mais influentes obras sobre a história do futebol no Brasil já haviam sido publicadas.

A primeira delas foi o livro de Mario Filho, O negro no futebol brasileiro, lançado em 1947, ${ }^{10}$ o qual tem provavelmente a maior influência na criação de um imaginário que ainda hoje marca a identidade do futebol no Brasil. $\mathrm{O}$ autor afirmou que produziu uma obra que "desafia contestação". ${ }^{11}$ Esse ponto de vista de Mario Filho foi compartilhado por muitos estudiosos de futuras gerações que utilizaram a obra do jornalista como fonte primordial (e desproblematizada) de seus trabalhos. ${ }^{12}$

Sua tese central reverberava as ideias de Gilberto Freyre e apostava no benefício da miscigenação, não do índio e do branco, como preconizavam as publicações do IHGB, mas no papel do negro e de seus descendentes, para

\footnotetext{
${ }^{8}$ Floriano Peixoto Correia, Grandezas e misérias do nosso futebol, Rio de Janeiro, Flores e Mano Editores, 1933, p. 16. 9/bidem, p. 21.

${ }^{10}$ Mario Filho, O negro no futebol brasileiro, 4 ed., Rio de Janeiro, Mauad, 2003.

"Ibidem, p. 23.

${ }^{12}$ Para a questão sobre os usos da obra de Mario Filho pela historiografia brasileira, ver o crucial debate realizado entre os seguintes autores: Antônio Jorge Soares, "História e invenção de tradições no campo do futebol", Estudos Históricos, vol. 13, n. 23, Rio de Janeiro, 1999, p. 119-146 (http://bibliotecadigital.fgv.br/ojs/ index.php/reh/article/view/2087/1226); Ronaldo Helal, Cesar Gordon Júnior, “Sociologia, história e romance na construção da identidade nacional através do futebol”, Estudos Históricos, vol. 13, n. 23, Rio de Janeiro, 1999, p. 147-165 (http://bibliotecadigital.fgv.br/ojs/index.php/reh/article/view/2092/1231); Antônio Jorge Soares, "A modo de resposta”, Estudos Históricos, vol. 13, n. 23, 1999, p. 166-173 (http://bibliotecadigital.fgv.br/ojs/index.php/reh/ article/view/2091/1230); Maurício Murad, "Considerações possíveis de uma resposta necessária”, Estudos Históricos, vol. 13, n. 24, Rio de Janeiro, 1999, p. 431-446 (http://bibliotecadigital.fgv.br/ojs/index.php/reh/article/ view/2094/1233); Carlos Leonardo Bahiense da Silva, "Sobre o negro no futebol brasileiro, de Mario Filho", In: Francisco Carlos Teixeira da Silva, Ricardo Pinto Dos Santos (orgs), Memória social dos esportes: futebol e política: a construção de uma identidade nacional, Rio de Janeiro, Mauad, 2006, p. $287-312$.
} 
a formação de uma maneira peculiar de se jogar futebol. Influenciado pelas ideias e métodos do sociólogo, Filho afirmou ao final do livro: "O futebol apagara a linha de cor. $O$ clube esquecendo-se que tinha preto no time, o preto esquecendo-se, de não lembrar mesmo, que era preto". ${ }^{13}$ Freyre, por sua vez, atestou a conclusão de Filho:

\begin{abstract}
Sublimando tanto do que é mais primitivo, mais jovem, mais elementar em nossa cultura, era natural que o futebol, no Brasil, ao engrandecer-se em instituição nacional, engrandecesse também o negro, o descendente de negro, o mulato, o cafuzo, o mestiço. E entre os meios mais recentes - isto é, dos últimos 20 ou 30 anos - de ascensão social do negro ou do mulato ou do cafuzo no Brasil, nenhum excede em importância o futebol. ${ }^{14}$
\end{abstract}

No entanto, uma observação mais cuidadosa do método utilizado pelo jornalista para chegar a tais conclusões é necessária. Mario Filho teve nos relatos orais sua principal fonte, baseando-se fundamentalmente em entrevistas com jogadores e dirigentes esportivos realizadas para a coluna Na Primeira

\title{
O livro Grandezas e misérias do futebol brasi- leiro deu ao esporte a direção das discussões política e social mais amplas em curso na so- ciedade brasileira
}

Fila, a qual era redigida para o jornal $O$ Globo desde 1942. Apesar de afirmar que utilizou outras fontes, como jornais e revistas, relatou na "Nota ao leitor" da primeira edição que: "as conversas com os próprios personagens da história do futebol brasileiro é que iam enriquecer o meu ensaio". ${ }^{15}$

O mesmo autor aproximava seu estudo de outras ciências sociais que utilizavam relatos orais como fontes, especialmente a Sociologia. Segundo ele, a voz do grupo de excluídos, cuja história não passava pelas atas e por outros documentos, seria encontrada apenas a partir dos relatos orais.

As atas e a correspondência dos clubes não atestam sobre os negros. As leis da entidade não faziam nem uma pequena menção às questões de raça, do negro propriamente dito. Estas se limitariam a levantar barreiras sociais, proibindo que trabalhadores braçais, empregados subalternos, contínuos, garçons, barbeiros, praças de pré etc. jogassem futebol em clubes filiados. "Eu fui, aos poucos, levantando o véu, ouvindo daqui, dali, reconstituindo a tradição oral, muito mais rica, muito mais viva do que a escrita dos documentos oficiais, graves, circunspectos, dos jornais que não dizem tudo". ${ }^{16}$

Em sua nota ao leitor publicada na primeira edição, Mario Filho lançou uma longa lista com nomes de quem entrevistara para a realização de sua

\footnotetext{
${ }^{13}$ Mario Filho, O negro no futebol brasileiro, 4 ed., Rio de Janeiro, Mauad, 2003., p. 342.

${ }^{14}$ Gilberto Freyre, "Prefácio à 1 a Edição", In: Mario Filho, op. cit., p. 25.

${ }^{15}$ Mario Filho, idem, p. 20.

${ }^{16}$ /bidem, p. 22
} 
obra. Ele divulgou 58 entrevistados, a maioria deles jogadores e dirigentes dos grandes clubes do Rio de Janeiro, sendo que apenas seis (pouco mais de 10\%) eram negros.

Portanto, por conta disso e apesar de todo o cuidado metodológico com que o autor diz ter procedido em sua investigação, é possível observar ao longo do livro a reprodução de diversos casos anedóticos, os quais possivelmente estavam enraizados na memória de seus entrevistados. Como exemplo, pode-se citar o caso de Robson. Ao receber uma carona de Orlando, seu companheiro no Fluminense, Robson teria repreendido o amigo quando este ofendia um casal de negros que quase os envolvera em um acidente. Segundo Mario Filho, Robson teria dito: "Não faz isso, Orlando. Eu já fui preto e sei o que é isso". ${ }^{17}$

Para Mario, que buscava retratar o passado do futebol brasileiro supostamente tal qual ele acontecera, a afirmação de Robson, assim como diversos outros episódios no decorrer da obra, estariam além da dúvida e eram apresentados como verdades irrefutáveis:

Eu não me teria valido da imaginação de romancista que ainda não publicou um romance? Não, eu não usei a imaginação. Nenhum historiador teria tido mais cuidado do que eu em selecionar os dados, em comprovar-lhe a veracidade por averiguações exaustivas. Às vezes uma simples dúvida me fazia inutilizar um capítulo, obrigando-me a novos trabalhos e pesquisas. ${ }^{18}$

Teria o autor "comprovado a veracidade" da história de Robson "por averiguações exaustivas"? Ainda que não seja possível determinar até que ponto ele efetivamente levou a cabo a eliminação dos relatos que geravam dúvidas ou quantos capítulos inutilizou devido a elas - o que é altamente improvável -, foi possível observar um esforço, ainda que meramente retórico, em se apontar uma metodologia, permitindo adotar a declaração mais fidedigna possível em busca de sua visão do que seria o trabalho de história: "a verdade pura e simples".19

É pertinente ressaltar que a historiografia brasileira de meados da década de 1940 ainda tinha uma forte presença dos ideais da escola metódica francesa, de finais do século XIX, que buscava a verdade científica na história, por meio da análise minuciosa dos documentos. O manual produzido por Langlois e Seignobos, Introdução aos estudos históricos, ${ }^{20}$ teve sua tradução brasileira publicada um ano antes do lançamento da primeira edição de $O$ negro no futebol brasileiro. Mario Filho estava em consonância com um modelo historiográfico que acreditava produzir a verdade inequívoca pela análise de documentos.

Escrevendo no mesmo período em que Filho e aparentemente baseando-se nos mesmos pressupostos, o jornalista Thomás Mazzoni publicou outro importante livro da historiografia do futebol no Brasil, História do futebol no Brasil 1894-1950, que foi lançado meses antes do início da Copa do Mundo. Mazzoni

\footnotetext{
${ }^{17}$ Mario Filho, O negro no futebol brasileiro, 4 ed., Rio de Janeiro, Mauad, 2003, p. 308.

${ }_{20}$ Publicado originalmente em 1898, o livro era um manual que "exprime exactamente o ponto de vista da 'escola metódica’ que domina a produção francesa entre 1880-1930” - Guy Bourdé, Hervé Martin, As escolas históricas, Lisboa, Europa-América, 1983, p. 102; ver também Charles-Victor Langlois; Charles Seignobos, Introdução aos estudos históricos, São Paulo, Renascença, 1946.
} 
estudou com afinco basicamente os grandes campeonatos e clubes, aos moldes das proposições historiográficas de seu período:

[...] por história devemos ter presente, em primeiro lugar, a participação do Brasil nos campeonatos internacionais, as disputas dos campeonatos nacionais, os jogos dos clubes brasileiros com os estrangeiros etc.; a implantação do futebol nos principais Estados, a fundação dos clubes de maior projeção nacional, os episódios e ocorrências que tiveram repercussão, interesse e movimento geral na vida do futebol no país. ${ }^{21}$

Como uma possível forma de distanciar seu trabalho da recém-publicada obra de Mario Filho, o autor buscou diferenciar o método que utilizava em seu trabalho daquele que fora empregado pelo jornalista carioca, enfatizando em seu "introito": "Não se trata, pois, de nenhuma história produzida pelo método 'ouvimos dizer', ou 'nos contaram assim e assado".22 Ele alega fundamentar-se em documentos que pareciam considerar "mais confiáveis", como notícias de jornais coletadas em um arquivo pessoal e uma "biblioteca especializada".23

\section{As atas e a correspondência dos clubes não atestam sobre os negros. As leis da entidade não faziam nem uma pequena menção às questões de raça, do negro propriamente dito}

A obra de Mazzoni é também a principal fonte de muitas pesquisas históricas sobre o futebol, sendo suas afirmações inquestionáveis. Ao apontar a introdução do futebol no Brasil em 1894 e Charles Miller como o "pai" do futebol no país, logo após ter indicado momentos esporádicos da prática do esporte em território nacional em datas anteriores ${ }^{24} \mathrm{o}$ mesmo declarou:

Considerando aqueles indícios méras conjunturas, enquadradas perfeitamente no capítulo da "origem do nosso futebol", mas não o documentando suficientemente, fomos por isso mais além, e resolvemos colher com os próprios contemporâneos do passado, cujos nomes estão vinculados à origem, fundação e propagação do nosso "soccer", os elementos que iniludivelmente nos autorizam a afirmar que São Paulo é a pioneira do futebol pátrio. ${ }^{25}$

A busca pela afirmação de São Paulo como origem do futebol nacional também não era casual. Em um período de grande rivalidade entre os dois maiores

\footnotetext{
${ }^{21}$ Thomás Mazzoni, História do futebol no Brasil 1895-1950, São Paulo, Edições Leia, 1950, p. 11.

22/bidem

${ }^{23}$ Ibidem

${ }^{24} \mathrm{O}$ autor cita que, no Brasil, o esporte "foi trazido também pelos marujos britânicos, que efetuaram as suas primeiras praticas nos capinzais desertos do litoral norte e sul do país, nos tempos coloniais, do fim do Império e da guerra do Paraguai". Thomás Mazzoni, História do futebol no Brasil 1895-1950, São Paulo, Edições Leia, 1950, p. 17

${ }^{25}$ /bidem, grifo nosso.
} 
centros esportivos do país, no qual cronistas e dirigentes esportivos do Rio de Janeiro e de São Paulo disputavam a primazia simbólica do futebol, ambos os autores contribuíram para a disputa. Se, por um lado, o livro de Mario Filho não aborda muito o futebol em São Paulo, centrando-se apenas na cidade do Rio de Janeiro, a obra de Mazzoni adota por diversas vezes, ainda que de forma sub-reptícia, um olhar e uma retórica privilegiando São Paulo.

Tais histórias tiveram grande influência sobre o futuro do futebol brasileiro. Desse modo, escritores, jornalistas e outros estudiosos buscaram nessas obras um conto de nosso futebol que pudessem recontar, sem se aventurar no exaustivo trabalho de pesquisa de fontes primárias, essenciais ao trabalho histórico.

\section{Terceira geração: anos 1970/1980}

A academia brasileira teve sua primeira aproximação com o estudo do futebol no final da década de $1970 .^{26}$ Dentre os historiadores, Joel Rufino dos Santos publicou, em 1978, um artigo na revista Encontros com a Civilização Brasileira, intitulado "Na Confederação Brasileira de Desportos (CBD) até o papagaio bate continência".27 $\mathrm{O}$ artigo, altamente panfletário, apresentou o futebol brasileiro como em estado de decadência, apontando o regime militar e a ausência de negros como as causas de dita crise.

O mesmo tom pode ser observado no livro publicado alguns anos depois, História Política do Futebol Brasileiro ${ }^{28}$ uma obra de caráter ensaístico, lançada por uma coleção que tinha por objetivo publicar trabalhos de história a um público não especializado.

Em tal livro, Santos realizou uma releitura da obra de Mario Filho - de forma aparentemente pouco crítica - , retratando como o futebol brasileiro teria se desenvolvido com a crescente participação dos trabalhadores, e como a crise que estaria estabelecida no final da década de 1970 tinha como sua principal causa a coerção dos mesmos pelas forças públicas nacionais. Estavam em curso o processo de abertura política e o término do regime da Ditadura Militar. Ao final, Joel Rufino deixou clara sua hipótese, ao creditar boa parte das mazelas do esporte exclusivamente ao regime autoritário, ao passo que a democracia que se aproximava era saudada como o momento em que tais problemas seriam resolvidos.

Com a (re)democratização, os tecnocratas serão afastados dos ministérios, como da CBF (Eles se parecem aos vampiros de Hollywood: se apanham sol, desmancham). Um novo modelo econômico-social de desenvolvimento proposto e discutido, não com os executivos das multinacionais, mas com os

\footnotetext{
${ }^{26} \mathrm{~A}$ dissertação de mestrado de Simoni Guedes, O futebol brasileiro: instituição zero, foi defendida no Museu Nacional, da Universidade Federal do Rio de Janeiro, em 1977. No mesmo ano, Muniz Sodré, em seu livro O monopólio da fala, trabalhou o esporte em seu último capítulo, "Futebol, teatro ou televisão?”. Simoni Lahud Guedes, O futebol brasileiro: instituição zero - Dissertação de mestrado, Rio de Janeiro, Programa de PósGraduação em Antropologia Social, Universidade Federal do Rio de Janeiro, 1977; Muniz Sodré, "Futebol, teatro ou televisão?", In: __. O monopólio da fala, Petrópolis, Vozes, 1977, p. 133-155.

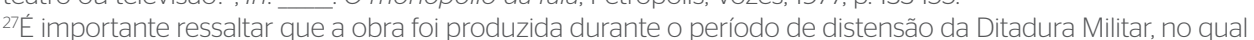
era possível tecer críticas abertas ao regime, o que podia ser visto em outros trabalhos. Ainda, Joel Rufino dos Santos foi opositor do regime ditatorial, tendo sido exilado e, após seu retorno ao país, foi preso e torturado. Joel Rufino Dos Santos, "Na CBD até o papagaio bate continência", Encontros com a Civilização Brasileira, Rio de Janeiro, n. 5, 1978, p. 119-129; Assim foi (se me parece), Rio de Janeiro, Rocco, 2008.

${ }^{28}$ Joel Rufino Dos Santos, História política do futebol brasileiro, Coleção Tudo é História, São Paulo, Brasiliense, 1981.
} 
trabalhadores. Aquilo que neste regime pareceu um bicho-desete-cabeças - dividir melhor o bolo - se fará. Vivendo melhor, o povo jogará mais futebol e fará um samba mais bonito pode ser na Marquês de Sapucaí mesmo. Os delfins e coutinhos serão esquecidos. Lembrados serão os frieds, os faustos, os leônidas, os zizinhos, os gasolinas e os garrinchas. ${ }^{29}$

Em 1982, houve a publicação de duas coletâneas de artigos, uma organizada no Rio de Janeiro e outra em São Paulo, possivelmente aproveitandose da euforia que acompanhava a seleção brasileira de futebol que disputaria a Copa do Mundo.

No Rio de Janeiro, Roberto DaMatta capitaneia a equipe de antropólogos do Museu Nacional da Universidade Federal do Rio de Janeiro (UFRJ) em Universo do futebol: esporte e sociedade brasileira. ${ }^{30}$ Em São Paulo, a Secretaria de Estado de Cultura patrocinou a obra organizada por José Carlos Sebe Bom Meihy e José Sebastião Witter, Futebol e cultura: coletânea de estudos, que é talvez a primeira em que o futebol é abordado por acadêmicos do campo da história. A mesma inclui importantes questionamentos, como o de Matthew G. Shirts, o qual apresenta uma das primeiras contestações à paternidade de Charles Miller de nosso futebol ao comentar sobre o discurso futebolístico no Brasil. Mas persistem releituras das teses de Mario Filho, como a de Robert Levine, que a atualiza até os dias da Ditadura Militar. ${ }^{31}$

Um dos textos fundamentais da coletânea é a introdução de José Carlos Sebe Bom Meihy, "Para que serve o futebol". O autor afirma que o futebol é um fenômeno histórico complexo e "exige um cuidado analítico que extrapole os limites da crônica ou das seguidas reelaborações dos pressupostos ideológicos de autores como Gilberto Freyre". ${ }^{32} \mathrm{O}$ texto continua tecendo uma dura crítica àqueles que procuraram ao longo da história usar o futebol para significar o povo brasileiro "incruento, malandrinho, gracioso e democrata", por isso, indeciso.

O povo jogador, torcedor, driblador, despolitizado e, por isso, "certo". Autores deste tipo de análises são os intelectuais da elite preocupados em mostrar "democracias". Rezadores, musicais e futebolistas são nossos atributos enquanto povo, segundo alguns, mas sem dúvida, o futebol merece outras explicações. ${ }^{33}$

Em um momento de debate político intenso sobre a democracia no país, Meihy encerrou sua introdução dialogando com seu contexto e exigindo melhores explicações para o futebol. Algo que pouco a pouco passou a caracterizar a produção historiográfica posterior.

\footnotetext{
${ }^{29}$ Joel Rufino Dos Santos, História política do futebol brasileiro, Coleção Tudo é História, São Paulo, Brasiliense, 1981, p. 93

30Roberto Damatta, Luiz Felipe B. Neves, Simoni L. Guedes; Arno Vogel, Universo do futebol: esporte e sociedade brasileira, Rio de Janeiro, Pinakotheke, 1982.

${ }^{31}$ José Carlos Sebe Bom Meihy, José Sebastião Witter (orgs.), Futebol e cultura: coletânea de estudos, São Paulo, Imprensa Oficial, Arquivo do Estado, 1982.

32José Carlos Sebe Bom Meihy, “Para que serve o Futebol?”, In: José Carlos Sebe Bom Meihy, José Sebastião Witter (orgs.), Futebol e cultura: coletânea de estudos, São Paulo, Imprensa Oficial, Arquivo do Estado, 1982, p. 12. 33/bidem, p. 19.
} 


\section{Quarta geração: anos 1990/2000}

Novamente na época de Copa do Mundo do futebol, surgiu uma das obras de maior importância à história de tal esporte na década de 1990, que se tornou referência para muitos estudos posteriores: Pontapé Inicial: memória do futebol brasileiro. ${ }^{34}$ Caldas se propôs a fazer uma análise em que busca uma concepção crítica de tal história, baseado em dados empíricos, sob a ótica da Sociologia, "considerando os aspectos políticos, sociais, econômicos e culturais que tanto movimentaram a sociedade brasileira da chamada Velha República" ${ }^{35}$

Caldas cometeu alguns equívocos metodológicos básicos quando afirmou que o objetivo de sua obra era "dar uma visão minuciosa do que foi o futebol brasileiro", e usou como material empírico, "principalmente os matutinos cariocas microfilmados na Biblioteca Nacional, jornais paulistas e, excepcionalmente, alguns poucos livros que tratam do tema". ${ }^{36}$ Isso fez com que se tornassem frequentes a reprodução de discursos tradicionais como o da origem do futebol brasileiro datada em 1894, "quando Charles Miller chega ao Brasil com uma bola de futebol". ${ }^{37}$ No entanto, tal livro foi importante para o debate sobre a história do futebol brasileiro ao lançar um olhar

\section{O texto continua tecendo uma dura crítica àqueles que procuraram ao longo da his- tória usar o futebol para significar o povo brasileiro "incruento, malandrinho, gracio- so e democrata}

sociológico sobre o projeto e por servir de referência para muitos estudos subsequentes sobre o tema.

A Copa de 1994 também proporcionou motivo para a reunião de acadêmicos a fim de analisar o esporte mais popular no país. Em São Paulo, o número 22 da Revista USP dedicou seu dossiê ao tema, com artigos de pesquisadores de renome, como Nicolau Sevcenko, Roberto DaMatta, Waldenyr Caldas, entre outros. Além do artigo de Sevcenko, "Futebol metrópoles e desatinos" que se tornaria um clássico da área -, vale destacar o de José Sergio Leite Lopes, "A vitória do futebol que incorporou a pelada", no qual foram relidas as teses de Mario Filho, apresentando-as como um projeto político. ${ }^{38}$

Também em 1994 foi publicada a primeira edição (na verdade, o número 0) da revista Pesquisa de Campo. Editada no Departamento de Ciências Sociais da Universidade do Estado do Rio de Janeiro, pelo extinto Núcleo

\footnotetext{
${ }^{34}$ Waldenyr Caldas, O pontapé inicial: memória do futebol brasileiro, São Paulo, Ibasa, 1990. 35 /bidem, p. 18

36/bidem.

${ }^{37}$ Ibidem

${ }^{38}$ Nicolau Sevcenko, “Futebol, metrópoles e desatinos", Revista USP, n. 22, São Paulo, 1994, p. 30-37 (http://www. usp.br/revistausp/22/04-nicolau.pdf); José Sergio Leite Lopes, "A vitória do futebol que incorporou a pelada”, Revista USP, n. 22, São Paulo, 1994, p. 64-83 (http://www.usp.br/revistausp/22/O8-josesergio.pdf).
} 
Permanente de Estudos de Sociologia do Futebol, tinha caráter interdisciplinar e publicava artigos de pesquisadores das mais diversas áreas.

Sem dúvidas, o livro que vem sendo mais usado como referência nos estudos atuais sobre a história do futebol no Brasil é o de Leonardo Pereira, Footballmania, publicado em 2000 e que encerra os trabalhos analisados neste artigo. Ainda, o mesmo apresenta aspectos positivos e um avanço metodológicos inegável, como o uso de vários tipos de fontes, para além dos periódicos. São atas de clubes e ligas de futebol de diferentes naturezas, legislação e documentação policial, livros de memória, peças de teatro e farta iconografia. Pereira também descortinou um enorme acervo de documentos sobre clubes e ligas de menor expressão no Rio de Janeiro, valorizando, pela primeira vez, o futebol praticado em pequenas agremiações. A contribuição e, principalmente, o estímulo causados com a publicação da obra fizeram com que ela pudesse ser considerada uma das mais importantes da historiografia recente.

Apesar de todo o avanço da pesquisa, Pereira ainda reproduziu o discurso do futebol "trazido por imigrantes europeus e por jovens que traziam da Europa as novidades do moderno esporte, ${ }^{39}$ o que fez com que tal esporte ganhasse na historiografia a marca de um jogo de elite. A primeira parte de sua análise percorre, mais uma vez, histórias de Charles Miller, em São Paulo, e Oscar Cox, no Rio de Janeiro, nomes que "ficariam imortalizados como grandes iniciadores do futebol no Brasil, buscando os motivos de sua devoção ao jogo e o sentido da operação que realizavam" ${ }^{40}$

A partir destes trabalhos, novos olhares estão se debruçando sobre a história do futebol no Brasil, levantando novas questões de elementos presentes nas histórias construídas sobre o esporte. Seria importante buscar os motivos da devoção ao futebol de Oscar Cox e Charles Miller "na tentativa de compreender o movimento que alimentou a consolidação do país" ? ${ }^{41}$ Estariam esses "jovens sportmen" realizando alguma operação? ${ }^{42}$ Seria realmente o futebol um jogo "fidalgo" ou estariam as camadas populares presentes em sua prática desde suas chegadas ao país? ${ }^{43}$

\section{Conclusões}

\footnotetext{
${ }^{39}$ Leonardo Pereira, Footballmania: uma história social do futebol no Rio de Janeiro, 1902-1938, Rio de Janeiro, Nova Fronteira, 2000, p. 16.

40/bidem.

${ }^{41}$ Ibidem, p. 14

${ }^{42}$ Como contraposição ao papel de Charles Miller, temos o exemplo do estudo do geógrafo Gilmar Mascarenhas de Jesus, que considera a base territorial do país como um fator ativo da dinâmica social. Desta maneira, o ritmo de evolução, o significado e o alcance do futebol em cada uma das principais cidades brasileiras, no início do século XX, variaram segundo as condições locais. A tese do autor liga a entrada do futebol no Sul do país a partir das colônias alemãs e da ligação do Rio Grande do Sul com países que já praticavam futebol desde princípios da segunda metade do século XIX, como Uruguai e Argentina. Gilmar Mascarenhas De Jesus, A bola nas redes e o enredo do lugar: uma geografia do futebol e de seu advento no Rio Grande do Sul, Tese (Doutorado em Geografia), Programa de pós-graduação em Geografia Humana, Universidade de São Paulo, 2001, 269 p.

${ }^{43}$ Recentemente, alguns trabalhos contestam este papel da elite na popularização do futebol. Em 2010, João Manuel Casquinha Malaia Santos apontou para uma forte cultura da formação de clubes modestos como motor de popularização da modalidade dentre as camadas menos abastadas. João Manuel Casquinha Malaia Santos, Revolução Vascaína: a profissionalização do futebol e inserção socioeconômica de negros e portugueses na cidade do Rio de Janeiro (1915-1934). Tese (Doutorado em História Econômica), Faculdade de Filosofia, Letras e Ciências Humanas, Universidade de São Paulo, São Paulo, 2010, 489 p. (http://www.teses. usp.br/teses/disponiveis/8/8137/tde-26102010-115906/pt-br.php).
} 
Nos últimos anos, o futebol vem sendo objeto de reflexão em inúmeros mestrados e doutorados de diversos programas de pós-graduação pelo país afora, em publicações científicas e em simpósios, seminários e congressos. ${ }^{44} \mathrm{Tal}$ avanço na produção tem débito com as produções analisadas. Cada qual, com seus avanços e lacunas, contribuiu e continua contribuindo para que seja possível refletir criticamente sobre o futebol praticado, assistido e recordado no Brasil.

Com isso, deve-se procurar não somente entender a história do futebol no Brasil, mas também a brasileira por meio da reflexão crítica deste esporte tão popular. O historiador não pode ser um cronista, não pode se refugiar na narrativa "como subterfúgio para não ter de explicar nem de resolver, portanto, os impasses da explicação. Contudo, eles estão presentes no seu relato e na crise força que venham à tona".45

Acredita-se que se deve chamar a atenção para as obras de fundamental importância à análise da história do futebol praticado no Brasil. No entanto, podem ser apontados também os mitos repetidos, os modelos de análise que continuam sendo reutilizados sem maior reflexão teórica e a tentação de tornar o que aconteceu em São Paulo e no Rio de Janeiro como expressão de todo o país - algo que os autores desses estudos não puderam resistir. Assim, é possível auxiliar na produção de pesquisas sobre futebol que ultrapassem os limites da narração.

\footnotetext{
${ }^{44}$ Sérgio Settani Giglio e Enrico Spaggiari apresentaram um panorama da produção em Ciências Humanas sobre futebol de 1990 a 2009. Sérgio Settani Giglio, Enrico Spaggiari, "A produção das ciências humanas sobre futebol no Brasil: um panorama (1990-2009)", Revista de História, n. 163, São Paulo, 2010, p. 293-350 (http://revhistoria.usp.br/images/stories/revistas/163/RH_163__13__Sergio_Giglio_e_Enrico_Spaggiari.pdf).

${ }^{45}$ Jorge Grenspan, "O lugar da história em tempos de crise", Revista de História, vol. 2, n. 151, São Paulo, 2004, p. 09-27 (http://revhistoria.usp.br/images/stories/revistas/151/RH_151___Jorge_Grespan.pdf).
} 
